\title{
Neurotensin receptor 1 immunoreactivity in the peripheral ganglia and carotid body
}

\author{
A. Porzionato, ${ }^{1}$ V. Macchi, ${ }^{1}$ A. Amagliani, ${ }^{1}$ I. Castagliuolo, ${ }^{2}$ A. Parenti, ${ }^{3}$ R. De Caro ${ }^{1}$ \\ ${ }^{1}$ Section of Anatomy, Department of Human Anatomy and Physiology; ' Department of Histology, \\ Microbiology, and Medical Biotechnologies; ${ }^{3}$ Section of Pathologic Anatomy, Department of Medical \\ Diagnostic Sciences and Special Therapies, University of Padova, Italy
}

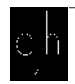

(C)2009 European Journal of Histochemistry

In the present study we investigated, through immunohistochemistry, the presence and location of neurotensin receptor 1 (NTR1) in the peripheral ganglia and carotid body of 16 humans and 5 rats. In both humans and rats, NTR1 immunostained ganglion cells were found in superior cervical ganglia (57.4 $\pm 11.6 \%$ and $72.4 \pm 11.4 \%$, respectively, $p<0.05)$, enteric ganglia $(51.9 \pm 10.4 \%$ and $64.6 \pm 6.1 \%, p<0.05)$, sensory ganglia $(69.2 \pm 10.7 \%$ and $73.0 \pm 13.1 \%, p>0.05)$ and parasympathetic ganglia $(52.1 \pm 14.1 \%$ and $59.4 \pm 14.0 \%, p>0.05)$, supporting a modulatory role for NT in these ganglia. Positivity was also detected in $45.6 \pm 9.2 \%$ and $50.8 \pm 6.8 \%$ of human and rat type I glomic cells, respectively, whereas type II cells were negative. Our findings suggest that NT produced by type I cells acts in an autocrine or paracrine way on the same cell type, playing a modulatory role on chemoception.

Key words: neurotensin receptor 1 , carotid body, autonomic ganglia, sensory ganglia, immunohistochemistry.

Correspondence: Raffaele De Caro,

Section of Anatomy, Department of Human Anatomy and Physiology, University of Padova,

Via A. Gabelli 65, 35121 Padova, Italy

Tel.: +39.049.8272321.

Fax: +39.049 .8272328 .

E-mail: rdecaro@unipd.it

\section{Paper accepted on June 16, 2009}

European Journal of Histochemistry

2009; vol. 53 issue 3 (July-September): 135-142
$\mathrm{N}$ eurotensin (NT) is a tridecapeptide which was first isolated from bovine hypothalamus (Carraway and Leeman, 1973) and is widely distributed in the nervous system and intestine. In the nervous system, neurotensin acts as a neurotransmitter and neuromodulator (Dobner, 2006); in the periphery, as a paracrine or endocrine factor (Mazzocchi et al., 1997; Malendowicz, 1998). It also acts as a growth factor on various cell types (Malendowicz, 1993; Markowska et al., 1994a, 1994b; Evers, 2006). Three different NT receptors, termed NTR1, NTR2 and NTR3, have been identified and cloned to date. NTR1 and NTR2 are, respectively, high- and low-affinity seven transmembrane domain $G$ protein-coupled receptors. NTR3 is a high-affinity single trans-membrane domain type 1 receptor, with $100 \%$ homology with the sorting protein, gp95/sortilin (Kitabgi, 2006; Mazella et al., 1998). NTR3 can also form heterodimers with NTRI in the plasma membrane (Martin et al., 2002). Nuclear internalization of the NTRI has been reported and has been suggested to play a role in the production of long-term genomic effects (Feldberg et al., 1998; Laduron, 1992). It has also been reported that NTR2, but not NTR1, returns to the plasma membrane after NT-induced sequestration (Mazella and Vincent, 2006).

In the peripheral nervous system, pregangliar fibers containing NT have been found in sympathetic, parasympathetic and enteric ganglia, and functional studies also suggest the expression of NTRs in ganglion cells. However, direct evidence of NTR1 protein expression in the different cell types of the ganglia has not yet been provided for human and rat. Only in rat dorsal root ganglia has evidence of NTR1 expression been given through hybridization in situ (Zhang et al., 1995), but there are no data on protein location or internalization.

The carotid body is an arterial chemoreceptor, sensitive to reductions in partial blood oxygen pres- 
sure and $\mathrm{pH}$ and to increases in partial $\mathrm{CO}_{2}$ pressure, the stimulation of which induces increases in ventilatory frequency and volume. The carotid body is situated at the carotid bifurcation, and is composed of parenchymal lobules separated by connective tissue, in which afferent fibers of the glossopharyngeal nerve, arising from the petrosal ganglion, occur (Porzionato et al., 2005). Two different cell populations are present in the carotid body: type I cells, in turn separated into light, dark and pyknotic, and type II cells, at the edges of the clusters. Post-ganglionic sympathetic nerve fibers from the superior cervical ganglion are present, innervating blood vessels and type I cells, and preganglionic parasympathetic and sympathetic fibers reaching ganglion cells near the glomic cells. NT has been detected in glomic cells (Heath et al., 1988; Heym and Kummer, 1989; Smith et al., 1990) but the presence of the corresponding receptors in the various glomic cell types has not yet been investigated.

Thus, the aim of the present study was to investigate, through immunohistochemistry, the presence and location of NTRI in the peripheral ganglia and carotid body of both human and rat, with particular reference to the different cell types.

\section{Materials and Methods}

Materials consisted of dorsal root ganglia, trigeminal ganglia, superior cervical ganglia, enteric (both myenteric and submucous) ganglia, and carotid bodies obtained at autopsy from 16 adult subjects (10 males, 6 females; mean age 44.3 years, Standard Deviation (SD) \pm 3.4 ), clinically negative for chronic pulmonary or cardiovascular diseases, and from 5 adult Wistar rats weighing 200-250 g. Samples for evaluation of enteric ganglia were taken at the level of the first jejunal loop. Further materials consisted in ciliary ganglia sampled from the above rats and pelvic ganglia sampled from the above humans. Autopsies were performed between 24 and 30 hours after death. Sampling from rats was performed soon after sacrifice.

Samples were fixed in neutral 10\% formalin and embedded in paraffin wax. Immunohistochemical examination was carried out on $3 \mu \mathrm{m}$ thick sections. Sections were incubated in $0.3 \%$ hydrogen peroxide for $10 \mathrm{~min}$ at room temperature, to remove endogenous peroxidase activity, and then in blocking serum $(0.04 \%$ bovine serum albumin
(A2153, Sigma-Aldrich, Milan, Italy) and 0.5\% normal goat serum (X0907, Dako Corporation, Carpinteria, CA, USA) in PBS) for 30 min. NTR1 immunoreactivity was detected with a rabbit polyclonal anti-NTR1 antibody at 1:600 dilution in blocking serum for 1 hour at room temperature. This antibody was raised against amino acids 1-28 and 50-69 of rat NTRI and also detected human NTR1 (Brun et al., 2005). Sections were then washed twice for $5 \mathrm{~min}$ in phosphate buffered saline (PBS), revealed with anti-rabbit serum for $20 \mathrm{~min}$ $\left(\right.$ DAKO $^{\circledR}$ EnVision + TM Peroxidase, Rabbit, Dako Corporation, Carpinteria, CA, USA), and developed in 3,3'-diaminobenzidine (DAB, Sigma-Aldrich, Milan, Italy). Lastly, sections were counterstained with hematoxylin. Negative controls were performed by omission of primary antibody. NTRI immunoreactions detected in rat and human substantia nigra were used as positive controls.

Immunohistochemistry anti-tyrosine hydroxylase ( $\mathrm{TH}$ ) was used to distinguish between sympathetic (TH-positive) and parasympathetic (TH-negative) human pelvic ganglia (Keast et al., 1995). To block endogenous peroxidase activity, rehydrated sections were incubated in $0.3 \%$ hydrogen peroxide for 10 min at room temperature and then predigested with $0.1 \%$ trypsin for antigen retrieval. After 2 rinses in PBS, sections were incubated for 30 min in blocking serum at room temperature to suppress nonspecific binding. Thereafter, sections were incubated in monoclonal mouse anti-human TH (DiaSorin, Stillwater, MN, USA, 1:1000, raised to TH purified from rat $\mathrm{PCl} 2$ cells) overnight at $4 \mathrm{C}^{\circ}$ and in biotinylated rabbit anti-mouse antibody (Elite Vecta Stain ABC Kit, Vector Laboratories, CA, 1:200) for 30 min. Lastly, sections were developed in 3,3'-diaminobenzidine (DAB, Sigma-Aldrich, Milan, Italy).

In the peripheral ganglia and carotid bodies, percentages of ganglion and glomic (types I and II) NTR1-positive cells, respectively, were evaluated at a magnification of $40 X$, and 5 sections and 3 fields per section were examined. Mean percentages were calculated for each case and for the entire series. For each human case, an average of 100 neurons were counted for sympathetic, parasympathetic and sensory ganglia, 40 neurons for enteric ganglia, 200 type I cells for carotid body. For each rat, an average of 200 neurons were counted for sympathetic and sensory ganglia, 150 neurons for parasympathetic ganglia, 50 neurons for enteric ganglia, 300 
type I cells for carotid body. Counterstaining with hematoxylin permitted differentiation between the light, dark and pyknotic cells of the carotid body, showing both positive and negative immunoreactions, according to the morphological characteristics and staining properties of the cells. The percentages of dark, light and pyknotic cells showing NTRI immunoreactivity were evaluated at a magnification of 40X, and 5 sections and 3 fields per section were examined. The mean percentages of positive dark, light and pyknotic cells were then calculated for each case and for the entire series.

The Mann-Whitney U-test was performed to verify any differences in NTRI immunoreactivity between human and rat samples and different types of carotid body cells and of sensory, enteric, sympathetic and parasympathetic ganglionic cells. In order to reveal differences between glomic type I cells and sensory (dorsal root and trigeminal ganglia), sympathetic (cervical superior ganglia), parasympathetic (ciliary and pelvic parasympathetic ganglia) and enteric ganglionic cells, statistical analysis was performed in both human and rat samples by the Kruskal-Wallis test and Dunn's multiple comparison test. A $p$ of 0.05 was considered significant.

In order to verify the immunohistochemical specificity of the reaction, absorption tests were also performed through incubation with the $\mathrm{N}$-terminal peptides used to generate the antiserum for 2 hours at room temperature.

\section{Results}

In both humans (Figure 1 ) and rats (Figure 2), NTR1 immunostaining was found in all the peripheral ganglia and carotid bodies examined. Ganglion and glomic cell immunostaining was eliminated when antiserum, preabsorbed with its peptide antigen, was used (Figures $1 B, 1 G, 2 B, 2 G$ ). As regards the subcellular location of NTRI immunostaining, in human superior cervical ganglia the percentage of nuclear positivity on the total was $34.2 \pm 16.3 \%$. In rat superior cervical ganglia and in sensory, parasympathetic and enteric ganglia of both humans and rats, NTRI positivity was almost only found in the nuclei of ganglion cells. In sensory ganglia, weak/moderate nuclear immunostaining was also found in some satellite cells. Positivity involved both A- and B-cells of the sensory ganglia, without statistically significant differences.

In both humans and rats, immunohistochemistry revealed the coexistence of both NTR1-positive and -negative type I cells in all specimens examined. When present, NTRI immunoreactivity was intense, and distributed in the cytoplasm or nucleus. The percentage of nuclear NTR1 immunostaining on the total was higher in rats $(65.4 \pm 12.9 \%)$ than in humans $(13.9 \pm 11.1 \% ; p<0.01)$. A preliminary analysis of subpopulations of type I cells did not reveal any statistically significant differences between dark, light or pyknotic cells $(p>0.05)$. Immunostained cells were distributed in both the center and periphery of the lobules. Type II cells did not show immunostaining.

In both humans and rats, the Kruskal-Wallis test revealed that the differences in NTRI immunostaining between the structures examined were statistically significant ( $p<0.001$ and $p=0.03$, respectively). In humans, Dunn's multiple comparison test revealed that NTRI immunostaining in sensory ganglia $(69.2 \pm 10.7 \%)$ was higher with respect to parasympathetic ganglia $(52.1 \pm 14.1 \%, p<0.01)$, enteric ganglia $(51.9 \pm 10.4 \%, p<0.01)$ and carotid bodies $(45.6 \pm 9.2 \%, p<0.001)$. Statistically significant differences were not found between pelvic sympathetic and parasympathetic ganglia. In rats, NTR1 immunostaining was significantly higher in sensory ganglia than carotid bodies $(73.0 \pm 13.1 \%$ versus $50.8 \pm 6.8 \%, p<0.001$ ) (Figure 3 ).

Mean percentages ( \pm SD) of NTRI immunostained ganglion cells were significantly higher with respect to human specimens in rat superior cervical $(72.4 \pm 11.4 \%$ versus $57.4 \pm 11.6 \%, p<0.05)$ and enteric ganglia $(64.6 \pm 6.1 \%$ versus $51.9 \pm 10.4 \%$, $p<0.05)$. NTR1 immunostaining of human pelvic parasympathetic ganglia $(52.1 \pm 14.1 \%)$ did not significantly differ from immunostaining of rat ciliary ganglia $(59.4 \pm 14.0 \%)$.

\section{Discussion}

NT has been found in the preganglionic axon terminals of the cat sympathetic paravertebral and prevertebral ganglia, but no NT immunoreactivity was detected in principal ganglion cells (Heym et al., 1984; Caverson et al., 1989; Maher et al., 1994; Zetina et al., 1999). Functional studies reveal release of NT from preganglionic axon terminals after stimulation (Caverson et al., 1989; 

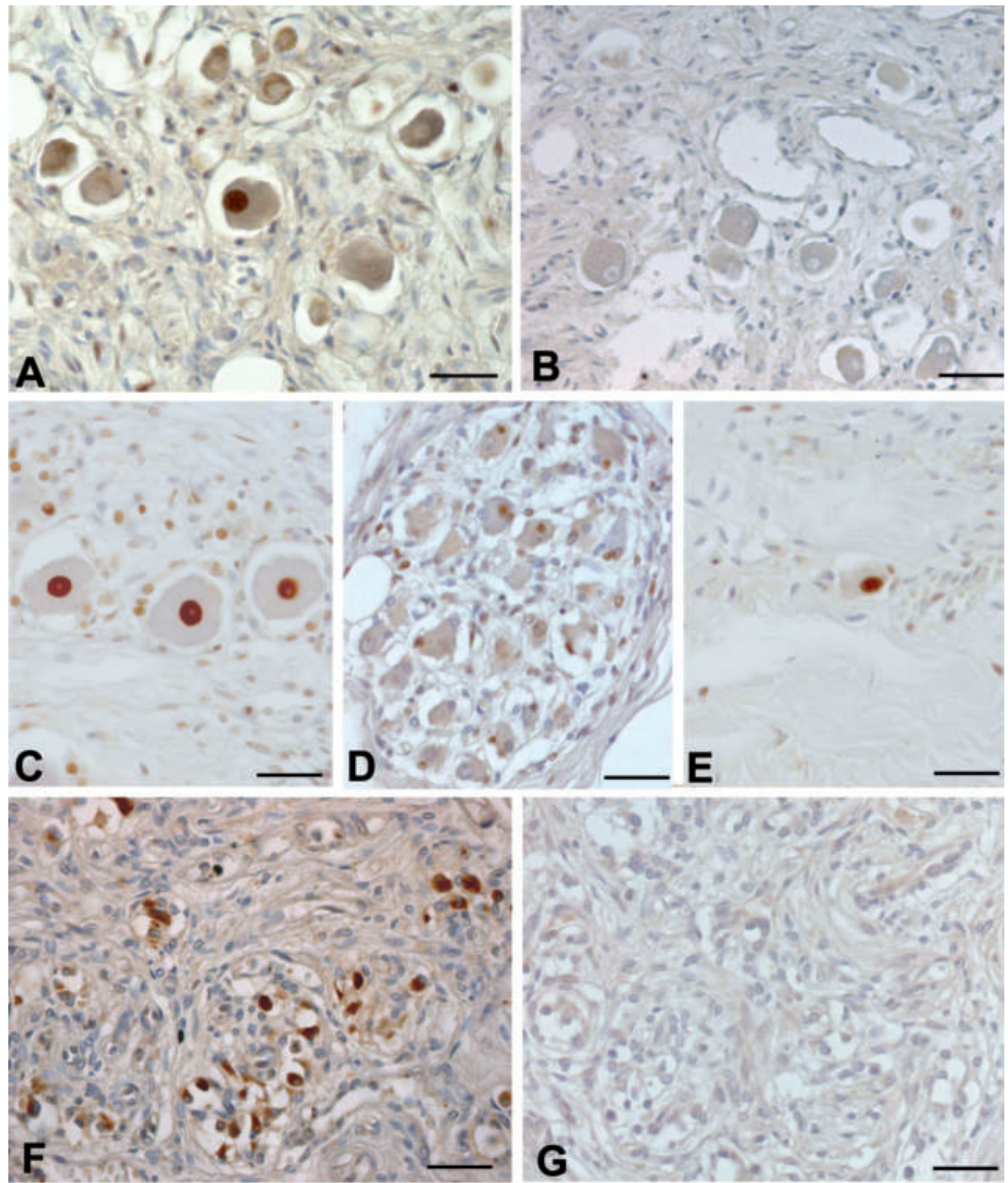

Figure 1. Anti-NTR1 immunohistochemistry in humans - Sections of superior cervical (A-B), trigeminal (C), pelvic parasympathetic (D), enteric (E) ganglia and carotid bodies (F-G), showing selective positivity of ganglionic cells (A, C-E) and glomic type I cells (F), while immunostaining is largely eliminated in negative controls (B, G), performed through absorption with the N-terminal peptides used to generate the antiserum. Scale bars $=30 \mu \mathrm{m}$. 

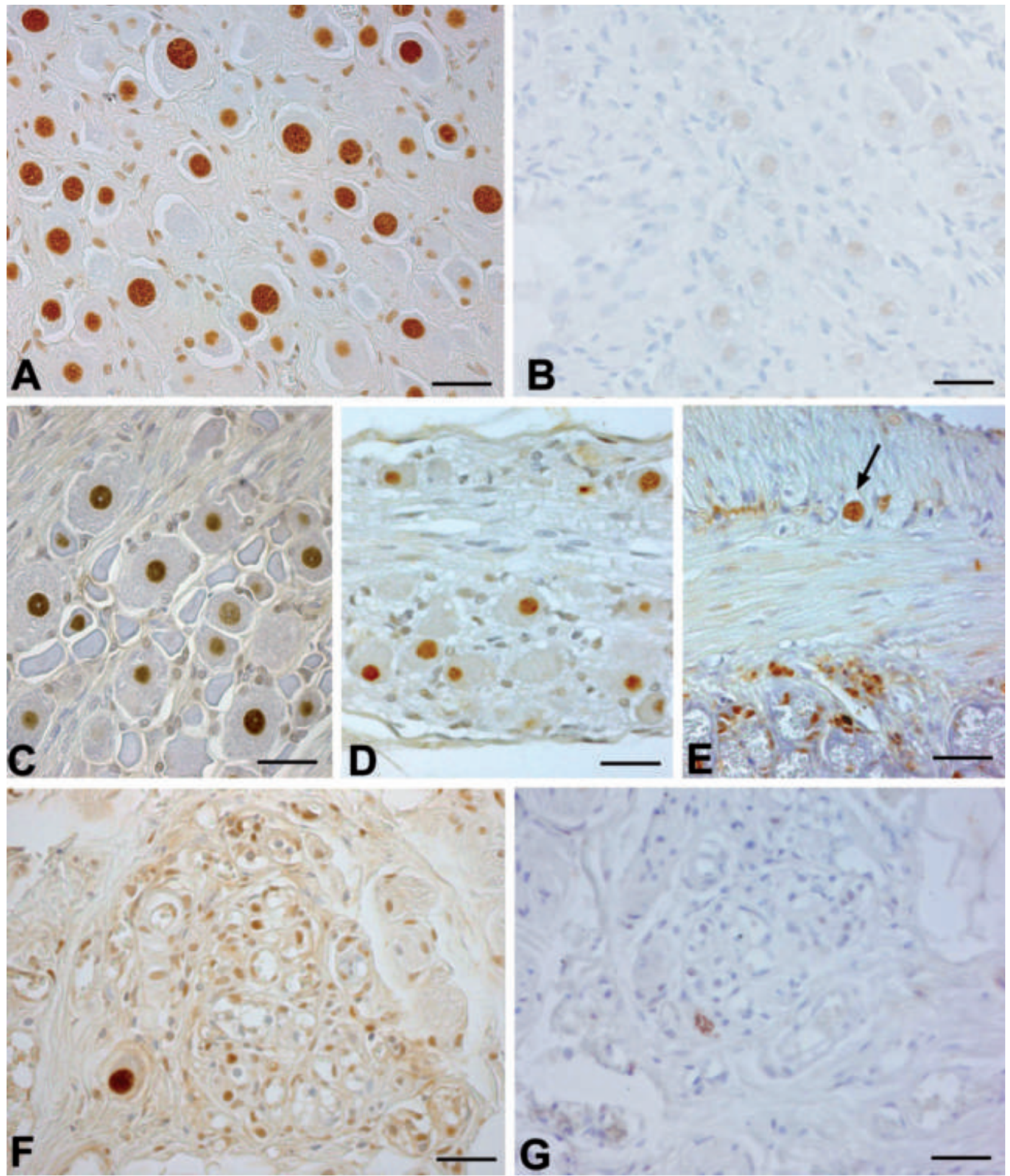

Figure 2. Anti-NTR1 immunohistochemistry in rats - Sections of superior cervical (A-B), trigeminal (C), ciliary parasympathetic (D), enteric (E) ganglia and carotid bodies (F-G), showing selective positivity of ganglionic cells (A, C-E) and glomic type I cells (F), while immunostaining is largely eliminated in negative controls $(B, G)$ performed through absorption with the $\mathrm{N}$-terminal peptides used to generate the antiserum. Scale bars $=\mathbf{3 0} \mu \mathrm{m}$. 


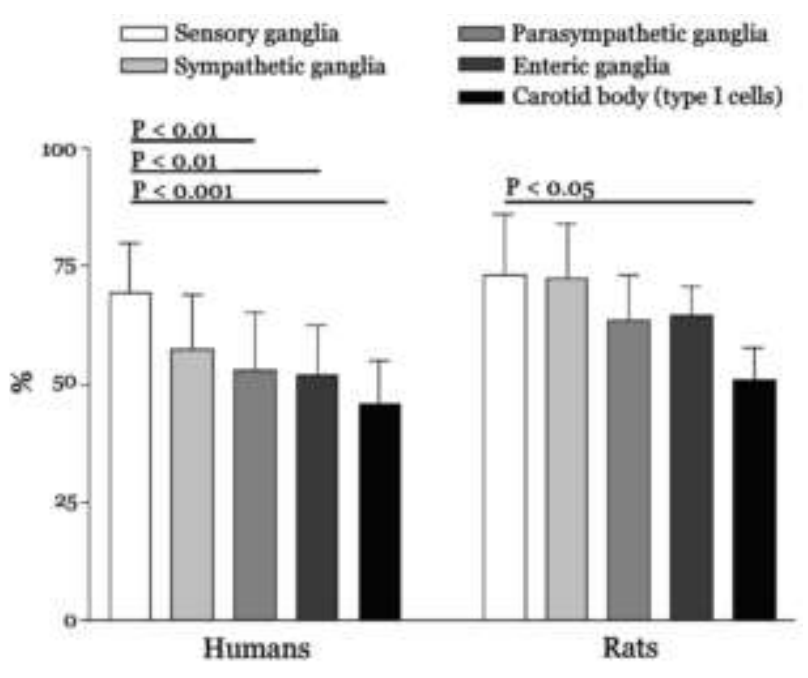

Figure 3. Mean values ( \pm SD) of percentages of NTR1 immunoreactivity in ganglionic and glomic type I cells of humans and rats. Sensory ganglia: trigeminal and dorsal root ganglia. Sympathetic ganglia: superior cervical ganglia (pelvic sympathetic ganglia not considered). Parasympathetic ganglia: pelvic parasympathetic ganglia in humans and ciliary ganglia in rats. Enteric ganglia: submucous and myenteric ganglia.

Maher et al., 1994) and excitation of sympathetic ganglion cells by exogen neurotensin (Bachoo and Polosa, 1988). Moreover, anti-NT immunohistochemistry shows NT internalization in ganglion cells after stimulation of preganglionic fibers, and this phenomenon is partially blocked by the NT antagonist SR48692 (Zetina et al., 1999). NTimmunoreactive fibers have also been found in mammalian parasympathetic intracardiac ganglia (Weihe and Reinecke, 1981; Reinecke et al., 1982), and sections from rat nodose ganglia incubated with 125I-NT exhibit dense radioautographic labeling of $15 \%$ of ganglion cells, with nuclear sparing (Kessler and Beaudet, 1989). NT-positive fibers have also been detected in canine submucous and myenteric ganglia (Buchan and Barber, 1987) and NT binding sites have been found, through autoradiography, in porcine (Seybold et al., 1990) and human (Azriel and Burcher, 2001) submucous and myenteric ganglia. Although the above studies strongly suggest the presence of high-affinity NT receptors on sympathetic, parasympathetic and enteric ganglion cells, this is the first work which identifies NTRI in rat and human ganglia by immunohistochemistry. Nuclear location of NTR1 has also been reported in other cell types (Boudin et al., 1998; Dana et al., 1989; Feldberg et al., 1998; Toy-Miou-Leong et al., 2004). For instance, electron microscopy analysis of the distribution of
NTR1 in rat substantia nigra by immunohistochemistry (Boudin et al., 1998; Toy-Miou-Leong et al., 2004) and autoradiography (Boudin et al., 1998) has revealed the strongest NTRI immunoreactivity and the highest number of 125I-NT binding sites in the nucleus with respect to other somatic structures. Mast cells have also been found to show particularly intense anti-NTR1 nuclear immunostaining (Feldberg et al., 1998). In the literature, nuclear location of NTRI has mainly been ascribed to internalization of the receptor (Boudin et al., 1998; Feldberg et al., 1998; Toy-Miou-Leong et al., 2004). NTR contains a strong nuclear targeting signal (Feldberg et al., 1998), and it has also been proposed that nuclear internalization of NT ligated to its receptor plays a role in the production of long-term genomic effects (Laduron, 1992). Nuclear localization has also been described for other G-protein-coupled receptors, such as angiotensin type 1, VIP, opioid, prostaglandin, and muscarinic receptors. However, it has also been alternatively hypothesized that nuclear location of NTRI could be ascribed to the presence of neosynthesized receptors, because the nuclear envelope has long been considered a major site of protein synthesis (Boudin et al., 1998). In the present work, suppression of nuclear immunostaining after absorption tests (Figures 1 and 2) confirms the specificity of our results.

Dorsal root ganglia are known to express different neurotransmitter receptors, such as nicotinic, muscarinic, glutamate and opioid receptors. NT immunoreactivity has also been found in the neurons of cat, dog, primate, sloth and rat dorsal root ganglia (Yaksh et al., 1988; Zhang et al., 1996). Electrophysiological studies on extirpated rat dorsal root ganglia after NT exposure showed outward and inward currents in C- and A-types neurons, respectively, suggesting the expression of different types of receptors (Xu et al., 1997). Inward currents in response to NT were also found in guineapig dorsal root ganglia (Kawarada et al., 2000). In situ hybridization revealed expression of NTRI mainly in small sensory neurons of rat dorsal root ganglia (Zhang et al., 1995), and immunofluorescence analysis revealed the expression of NTR2 in both small and large cells (Sarret et al., 2005). We also confirmed by immunohistochemistry NTRI expression in sensory ganglion cells, and nuclear NTR1 location supports internalization, also in this structure. In addition, in both humans and rats it 
must be stressed that the sensory ganglia showed the highest NTRI immunostaining among the different structures examined.

Many neurotransmitters and neuromodulators have been identified in glomic cells, such as dopamine, serotonin, noradrenaline, adrenaline, acetylcholine, adenosine, met- and leu-enkephalins, neuropeptide Y, CGRP, galanin, endothelins, bombesin, $\mathrm{NO}$ and adrenomedullin (Bairam and Carroll, 2005; Porzionato et al., 2006, 2008a, 2008b). NT occurrence and distribution has been studied by radioimmunoassay (Heath et al., 1988), immunohistochemistry (Heym and Kummer, 1989) and immunogold techniques (Smith et al., 1990). In human carotid bodies, radioimmunoassay showed higher levels of NT expression than VIP and substance $P$, and lower levels of bombesin, met- and leu-enkephalin (Heath et al., 1988). The immunogold technique revealed the weakest immunoreactivity for neurotensin with respect to the other neuropeptides (Smith et al., 1990). A species-specific pattern of NT expression was also reported, with NT immunolabeling only in beagle glomus cells among various animal species (Heym and Kummer, 1989). The location of NTRI in the carotid body has never been investigated before, so that our study demonstrates for the first time the selective expression of NTRI in human and rat type I cells. In some cases, immunoreaction was cytoplasmic and in others nuclear, thus also confirming NT internalization in the carotid body. The higher cytoplasmic NTRI positivity in humans than in rats may be explained on the basis of the different kinetics of internalization, or longer post-mortem intervals. Thus, NT produced by type I cells may act in an autocrine or paracrine way on the same cell type. It is possible that NT acting on type I cells also derives from NT-positive sympathetic or parasympathetic fibers innervating type I cells, although there is no direct evidence of this in the literature. NT probably plays a modulatory role on chemoception by type I cells, as the neuromodulatory effects of NT have already been proposed in ganglion transmission (Bachoo and Polosa, 1988). Further functional studies will be necessary to understand the effect of NT in glomic cells. Binding of NT to NTRI stimulates phosphorylation of ERK and AKT (Hassan et al., 2004) and probably contributes to the activation of ERK and AKT signalling pathways in the carotid body and peripheral ganglia (Porzionato et al., In press). Cell line
PC12, which shows oxygen-sensing properties and has been considered as a model for carotid body function, cannot be used for investigation of NT action, as these cells express and release neurotensin (Tischler et al., 1991) but seem not to show functional NTR (Caillaud et al., 1995). However, it is intriguing to note that NT attenuates dopamine-induced inhibition of midbrain dopamine neurons (Seutin et al., 1989; Shi et al., 1992), as dopamine is the main glomic neurotransmitter. It may be hypothesized that, also in the carotid body, NT reduces the inhibitory effect of dopamine on chemoception.

\section{Acknowledgments}

The authors are grateful to Giuliano Carlesso, Gloria Sarasin and Anna Rambaldo for skillful technical assistance.

\section{References}

Azriel Y, Burcher E. Characterization and autoradiographic localization of neurotensin binding sites in human sigmoid colon. J Pharmacol Exp Ther 2001;297:1074-81.

Bachoo M, Polosa C. Cardioacceleration produced by close intra-arterial injection of neurotensin into the stellate ganglion of the cat. Can J Physiol Pharmacol 1988;66:408-12.

Bairam A, Carroll JL. Neurotransmitters in carotid body development. Respir Physiol Neurobiol 2005;149:217-32.

Boudin H, Pelaprat D, Rostene W, Pickel VM, Beaudet A. Correlative ultrastructural distribution of neurotensin receptor proteins and binding sites in the rat substantia nigra. J Neurosci 1998;18:847384.

Brun P, Mastrotto C, Beggiao E, Stefani A, Barzon L, Sturniolo GC, et al. Neuropeptide neurotensin stimulates intestinal wound healing following chronic intestinal inflammation. Am J Physiol Gastrointest Liver Physiol 2005;288:G621-29.

Buchan AM, Barber DL. Neurotensin-containing neurons in the canine enteric innervation. Neurosci Lett 1987;76:13-7.

Caillaud T, Opstal WY, Scarceriaux V, Billardon C, Rostene W. Treatment of PC12 cells by nerve growth factor, dexamethasone, and forskolin. Effects on cell morphology and expression of neurotensin and tyrosine hydroxylase. Mol Neurobiol 1995; 10:105-14.

Carraway $\mathrm{R}$, Leeman SE. The isolation of a new hypotensive peptide, neurotensin, from bovine hypothalami. J Biol Chem 1973; 248:6854-61.

Caverson MM, Bachoo M, Ciriello J, Polosa C. Effect of preganglionic stimulation or chronic decentralization on neurotensin-like immunoreactivity in sympathetic ganglia of the cat. Brain Res 1989;482:365-70

Dana C, Vial M, Leonard K, Beauregard A, Kitabgi P, Vincent JP, et al. Electron microscopic localization of neurotensin binding sites in the midbrain tegmentum of the rat. I. Ventral tegmental area and the interfascicular nucleus. J Neurosci 1989;9:2247-57.

Dobner PR. Neurotensin and pain modulation. Peptides 2006; 27:2405-14.

Evers BM. Neurotensin and growth of normal and neoplastic tissues. Peptides 2006; 27:2424-33.

Feldberg RS, Cochrane DE, Carraway RE, Brown E, Sawyer R, Hartunian $M$, et al. Evidence for a neurotensin receptor in rat serosal mast cells. Inflamm Res 1998;47:245-50.

Hassan S, Dobner PR, Carraway RE. Involvement of MAP-kinase, 
PI3-kinase and EGF-receptor in the stimulatory effect of Neurotensin on DNA synthesis in PC3 cells. Regul Pept 2004; 120:155-66.

Heath D, Quinzanini M, Rodella A, Albertini A, Ferrari R, Harris P. Immunoreactivity to various peptides in the human carotid body. Res Commun Chem Pathol Pharmacol 1988;62:289-93.

Heym C, Reinecke M, Weihe E, Forssmann WG. Dopamine-betahydroxylase-, neurotensin-, substance $P_{-}$-, vasoactive intestinal polypeptide- and enkephalin-immunohistochemistry of paravertebral and prevertebral ganglia in the cat. Cell Tissue Res 1984; 235:411-8.

Heym C, Kummer W. Immunohistochemical distribution and colocalization of regulatory peptides in the carotid body. J Electron Microsc Tech 1989;12:331-42.

Kawarada S, Unno T, Ohashi H, Komori S. Neurotensin-induced $\mathrm{Cl}(-)$ current in guinea-pig dorsal root ganglion cells. Eur J Pharmacol 2000;404:69-78.

Keast JR, Luckensmeyer GB, Schemann M. All pelvic neurons in male rats contain immunoreactivity for the synthetic enzymes of either noradrenaline or acetylcholine. Neurosci Lett 1995; 196:209-12.

Kessler JP, Beaudet A. Association of neurotensin binding sites with sensory and visceromotor components of the vagus nerve. J Neurosci 1989; 9:466-72

Kitabgi P. Functional domains of the subtype 1 neurotensin receptor (NTS1). Peptides 2006;27:2461-8.

Laduron PM. Toward genomic pharmacology: from membranal to nuclear receptors. Adv Drug Res 1992;22:107-48.

Maher E, Bachoo B, Polosa C. In vitro and in vivo evidence of neurotensin release from preganglionic axon terminals in the stellate ganglion of the cat. Brain Res 1994;640:131-5.

Malendowicz LK. Involvement of neuropeptides in the regulation of growth, structure and function of the adrenal cortex. Histol Histopathol 1993;8:173-86.

Malendowicz LK. Role of neuromedins in the regulation of adrenocortical function. Horm Metab Res 1998;30:374-83.

Markowska A, Nussdorfer GG, Malendowicz LK. Different effects of neurotensin and neuromedin- $\mathrm{N}$ on the proliferative activity of rat adrenal cortex. Histol Histopathol 1994a;9:449-52.

Markowska A, Nussdorfer GG, Malendowicz LK. Proliferogenic effect of neurotensin (NT) and neuromedin-N (NMN) on the rat adrenal cortex: evidence that angiotensin-II mediates the effect of $\mathrm{NMN}$, but not of NT. Neuropeptides 1994b;27:91-4.

Martin S, Navarro V, Vincent JP, Mazella J. Neurotensin receptor-1 and -3 complex modulates the cellular signaling of neurotensin in the HT29 cell line. Gastroenterology 2002;123:1135-43.

Mazella J, Zsurger N, Navarro V, Chabry J, Kaghad M, Caput D, et al. The 100-kDa neurotensin receptor is gp95/sortilin, a non-G-proteincoupled receptor. J Biol Chem 1998;273:26273-6.

Mazella J, Vincent JP. Internalization and recycling properties of neurotensin receptors. Peptides 2006; 27:2488-92.

Mazzocchi G, Malendowicz LK, Rebuffat P, Gottardo G, Nussdorfer GG. Neurotensin stimulates $\mathrm{CRH}$ and ACTH release by rat adrenal medulla in vitro. Neuropeptides 1997;31:8-11.

Porzionato A, Macchi V, Guidolin D, Parenti A, Ferrara SD, De Caro R. Histopathology of carotid body in heroin addiction. Possible chemosensitive impairment. Histopathology 2005;46:296-306.

Porzionato A, Macchi V, Belloni AS, Parenti A, De Caro R. Adrenomedullin immunoreactivity in the human carotid body. Peptides 2006;27:69-73.
Porzionato A, Macchi V, Parenti A, Matturri L, De Caro R. Peripheral chemoreceptors: postnatal development and cytochemical findings in Sudden Infant Death Syndrome. Histol Histopathol 2008a; 23:351-65.

Porzionato A, Macchi V, Parenti A, De Caro R. Trophic factors in the carotid body. Int Rev Cell Mol Biol 2008b;269:1-58.

Porzionato A, Macchi V, Parenti A, De Caro R. Extracellular signalregulated kinase and phosphatidylinositol-3-kinase/AKT signalling pathways in the human carotid body and peripheral ganglia. Acta Histochem In press.

Reinecke M, Weihe E, Carraway RE, Leeman SE, Forssmann WG. Localization of neurotensin immunoreactive nerve fibers in the guinea-pig heart: evidence derived by immunohistochemistry, radioimmunoassay and chromatography. Neuroscience 1982; 7:1785-95.

Sarret P, Esdaile MJ, Perron A, Martinez J, Stroh T, Beaudet A. Potent spinal analgesia elicited through stimulation of NTS2 neurotensin receptors. J Neurosci 2005;25:8188-96.

Seybold VS, Treder BG, Aanonsen LM, Parsons A, Brown DR. Neurotensin binding sites in porcine jejunum: biochemical characterization and intramural localization. Synapse 1990;6:81-90.

Seutin V, Massotte L, Dresse A. Electrophysiological effects of neurotensin on dopaminergic neurones of the ventral tegmental area of the rat in vitro. Neuropharmacology 1989;28:949-54.

Shi WX, Bunney BS. Roles of intracellular CAMP and protein kinase A in the actions of dopamine and neurotensin on midbrain dopamine neurons. J Neurosci 1992;12:2433-8.

Smith P, Gosney J, Heath D, Burnett H. The occurrence and distribution of certain polypeptides within the human carotid body. Cell Tissue Res 1990;261:565-71.

Tischler AS, Ruzicka LA, DeLellis RA. Regulation of neurotensin content in adrenal medullary cells: comparison of PC12 cells to normal rat chromaffin cells in vitro. Neuroscience 1991;43:671-8.

Toy-Miou-Leong M, Bachelet CM, Pelaprat D, Rostene W, Forgez P. NT agonist regulates expression of nuclear high-affinity neurotensin receptors. J Histochem Cytochem 2004;52:335-45.

Weihe $E$, Reinecke M. Peptidergic innervation of the mammalian sinus nodes: vasoactive intestinal polypeptide, neurotensin, substance P. Neurosci Lett 1981;26:283-8.

Xu ZQ, Zhang X, Grillner S, Hokfelt T. Electrophysiological studies on rat dorsal root ganglion neurons after peripheral axotomy: changes in responses to neuropeptides. Proc Natl Acad Sci USA 1997; 94:13262-6.

Yaksh TL, Michener SR, Bailey JE, Harty GJ, Lucas DL, Nelson DK, et al. Survey of distribution of substance $P$, vasoactive intestinal polypeptide, cholecystokinin, neurotensin, Met-enkephalin, bombesin and PHI in the spinal cord of cat, dog, sloth and monkey. Peptides 1988; 9:357-72.

Zetina ME, Jimenez B, Diaz-Luna F, Mora-Valladares E, Morales MA. Release-depletion and receptor-mediated neuronal internalization of endogenous neurotensin in the stellate ganglion of the cat. Neuroscience 1999;92:655-64.

Zhang X, Xu ZQ, Bao L, Dagerlind A, Hokfelt T. Complementary distribution of receptors for neurotensin and NPY in small neurons in rat lumbar DRGs and regulation of the receptors and peptides after peripheral axotomy. J Neurosci 1995;15:2733-47.

Zhang X, Bao L, Xu ZQ, Diez M, Frey P, Hokfelt T. Peripheral axotomy induces increased expression of neurotensin in large neurons in rat lumbar dorsal root ganglia. Neurosci Res 1996;25:359-69. 